Muro de la Investigación, 2020(1), enero-junio ISSN : 2523-2886

Doi: https://doi.org/10.17162/rmi.v5i1.1300

\title{
Financiamiento y desarrollo empresarial en las MYPES residentes en el parque industrial de Huaycán
}

\author{
Financing and business development in the MYPES resident in the industrial park \\ of Huaycán
}

\author{
Ingrid Lizeth Tanta Espinoza, ${ }^{1}$ Abigail Elizabeth Vilca Coaquira ${ }^{2 a}$ y \\ Gloria Ivon Luy Medina ${ }^{3}$ \\ Universidad Peruana Unión, Lima, Perú123
}

Recibido: 07 de diciembre de $2019 \quad$ Aceptado: 05 de enero de 2020

\begin{abstract}
Resumen
La presente investigación analiza la relación entre el financiamiento y desarrollo empresarial de las MYPES (Micro y Pequeñas Empresas) residentes en la zona industrial de Huaycán, ciudad del distrito de Ate-Vitarte, Lima. El estudio es de tipo descriptivo correlacional con un diseño no experimental y de corte transversal. La población en estudio estuvo formada por 60 MYPES en el mencionado lugar. A fin de medir el financiamiento interno se utilizó un cuestionario elaborado por Márquez (2007). Para medir el financiamiento externo se utilizó un cuestionario creado por Cornejo y Galicia (2010); el cuestionario de desarrollo empresarial fue elaborado por García (2003). Su fiabilidad se verificó por el alfa de Cronbach, que para el financiamiento obtuvo $0.95 \mathrm{y}$ para el desarrollo empresarial 0.840. Los resultados de Rho de Spearman $\rho=0.329, p=$ 0.036 permite concluir que el financiamiento tiene una relación significativa directa sobre el desarrollo empresarial. Entonces, a mayor financiamiento las MYPES tendrán mayor desarrollo empresarial que les permitirá tener un desempeño óptimo en sus actividades que involucran a gran parte de la población, permitiéndoles tener una oportunidad de negocio y empleo, mejorando de esta manera la economía de sus familias, a fin de propiciar la reducción de pobreza en el país.
\end{abstract}

Palabras clave: Financiamiento, Desarrollo, MYPES, Competitivas, industria, economía

\begin{abstract}
This research analyzes the relationship between financing and business development of the MYPES (Micro and Small Businesses) residing in the industrial zone of Huaycán, a city located in the Ate-Vitarte district, Lima. The study is descriptive correlational type with a non-experimental and cross-sectional design. The study population consisted of 60 MYPES in the mentioned place. In order to measure internal financing, a questionnaire prepared by Márquez (2007) was used. To measure external financing, a questionnaire created by Cornejo and Galicia (2010) was used; The business development questionnaire
\end{abstract}

\footnotetext{
a CORRESPONDENCIA AL AUTOR
}

EMAIL: abigailvilca@upeu.edu.pe 
was prepared by García (2003). Its reliability was verified by Cronbach's alpha, which obtained 0.95 for financing and 0.840 for business development. The Spearman's Rho results $\rho=0.329, p=0.036$ allow us to conclude that financing has a significant direct relationship on business development. Therefore, the more financing the MYPES will have, the more business development will allow them to perform optimally in their activities that involve a large part of the population, allowing them to have a business and employment opportunity, thus improving the economy of their families, in order to promote poverty reduction in the country.

Keywords: Financing, Development, MYPES, Competitive, industry, economy

\section{Introducción}

El desarrollo de las MYPES a nivel mundial tiene una clasificación primordial; por ejemplo, en Europa las MYPES forman parte del 95\% de las empresas de la ciudad, por lo que cumplen una actividad importante de desarrollo; en México también es considerable el crecimiento de estas unidades, dado que contribuyen con el total de la mano de obra ocupada y contribuyen directamente al PBI (Algieri, 2007).

En el escenario nacional, las MYPES representan el 99.1\% del total de empresas que operan en el país, y el 46,8\% del total de las unidades económicas se encuentran ubicadas en la Provincia de Lima y en la Provincia Constitucional del Callao, lo cual confirma el grado de concentración empresarial en estos ámbitos geográficos (INEI, 2017). En este contexto, se ha optado a crear puntos de concentración productiva y comercial: los denominados "Parques industriales", que comprenden una zona eminentemente productiva desde el año 1996, que congrega a las MYPES con diversas actividades de producción y comercialización (Garma, 2016).

Sin embargo, su desarrollo se va pausando por el mínimo apoyo que reciben del gobierno central y local, recibiendo más atención de organismos externos (ONG). Ademas, por su estatus de MYPES, tienen dificultades para acceder al financiamiento externo: a nivel nacional, el crédito financiero a las MYPES ascendía a 2’793,814.00 soles, de los cuales casi el 85\% los brindaba la Banca Múltiple y las Cajas Municipales para su desarrollo, dicho resultado hace imaginar el nivel de significancia que tienen el financiamiento en el desarrollo de las MYPES (Prompyme, 2004).

Según el último reporte de SBS del Perú, la cajas que acceden al mayor porcentaje de MYPES son: la Caja Municipal Arequipa S.A y la Caja Municipal Huancayo S.A, precisamente en la zona de nuestra investigación las MYPES acceden 
mensualmente por un total de S/ 39, 479,676.00, no obstante mencionar que existe un ratio de morosidad por ellas mismas de $2.85 \%$.

Por lo expuesto anteriormente, es necesario determinar como el financiamiento se relaciona con el desarrollo de las MYPES en el parque industrial de Huaycán, propiciando, motivando y generando espacios de competencia y competitividad, operacionalizadas en el aumento tanto de la productividad como del nivel de sus ingresos.

\section{Método}

La presente investigación es de tipo correlacional, porque se plantea encontrar la relación entre el financiamiento y el desarrollo empresarial de las MYPES del parque industrial de Huaycán durante el período 2018. El diseño de investigación es no experimental, porque no se manipularon las variables de estudio durante la investigación. Y es transversal porque los datos se toman en un solo momento. La población consistió en 60 gerentes de las MYPES residentes en dicha zona.

El instrumento usado para medir la variable Financiamiento es el elaborado por Márquez (2007), que aplicó una escala de dos subvariables, la primera: financiamiento interno, que comprende las dimensiones de depreciación (2 ítems), aportación de socios (3 ítems), realización de activos (3 ítems) y reinversión de utilidades (2 ítems) y la segunda: financiamiento externo, que comprende las dimensiones de financiamiento público (9 ítems) y financiamiento privado (16 ítems); se trabajó con una muestra probabilística de 384 empresarios residentes en México D. F., y fue validado bajo el análisis de alfa de Cronbach de 0.825 (82.5\%) otorgándole alta fiabilidad.

Para medir la variable Desarrollo empresarial, el cuestionario utilizó una escala que consta de cinco dimensiones: personas (11 ítems), producto (4 ítems), tecnología (5 ítems), procesos (8 ítems), y nivel de ingresos (7 ítems); las que se basaron en el instrumento elaborado por García (2003). Para medir los ítems se utilizó la escala de Likert de 5 puntos, donde: Definitivamente Si (5), Probablemente Si (4), A veces (3), Probablemente No (2), Definitivamente No (1).

\section{Resultados}

Para obtener los resultados primero se aplicó la estadística descriptiva. Luego, se realizó el análisis inferencial, y para ello se utilizó la prueba estadística de correlación 
Rho de Spearman. Resultados sobre el financiamiento de las MYPES en el parque industrial de Huaycán. La evaluación de financiamiento en cuanto a las fuentes y su nivel de alcance en las MYPES, son los siguientes:

\section{Tabla 1}

Alcance de las fuentes de financiamiento usadas por las MYPES, del parque industrial de Huaycán

\begin{tabular}{l|c|c|c|}
\hline \multirow{2}{*}{ Fuentes de financiamiento } & \multicolumn{3}{|c|}{ Alcance } \\
\cline { 2 - 4 } & Bajo & Medio & Alto \\
\hline Depreciación & $46.7 \%$ & $53.3 \%$ & $0.0 \%$ \\
Aportación de Socios & $36.7 \%$ & $63.3 \%$ & $0.0 \%$ \\
Realización de Activos & $35.0 \%$ & $36.7 \%$ & $28.3 \%$ \\
Utilidades reinvertidas & $56.7 \%$ & $43.3 \%$ & $0.0 \%$ \\
Financiamiento Público & $33.3 \%$ & $40.0 \%$ & $26.7 \%$ \\
Financiamiento Privado & $31.7 \%$ & $40.0 \%$ & $28.3 \%$ \\
\hline Financiamiento & $31.7 \%$ & $45.0 \%$ & $23.3 \%$ \\
\hline
\end{tabular}

Asimismo, se presentan los resultados de los indicadores según las dimensiones del financiamiento al que acceden las MYPES en el parque industrial de Huaycán.

\section{Tabla 2}

Resultados de las dimensiones e indicadores del financiamiento que perciben las MYPES del parque industrial de Huaycán

\begin{tabular}{|c|c|c|c|}
\hline $\mathbf{N}^{\circ}$ & Preguntas & Med & Prom \\
\hline \multicolumn{4}{|c|}{ Depreciación } \\
\hline \multirow{2}{*}{1} & $\begin{array}{l}\text { ¿Usa usted el fondo de depreciación de sus equipos para } \\
\text { renovarlos? }\end{array}$ & 4.7 & \multirow[b]{2}{*}{$(4.60)$} \\
\hline & $\begin{array}{l}\text { ¿Usa usted el fondo de depreciación de un determinado } \\
\text { equipo, como financiamiento en pro de la adquisición de } \\
\text { equipos diferentes? }\end{array}$ & 4.5 & \\
\hline \multicolumn{4}{|c|}{ Aporte de Socios } \\
\hline 3 & $\begin{array}{l}\text { ¿Usted financia su actividad productiva con la aportación de } \\
\text { socios? }\end{array}$ & 4.03 & \multirow{3}{*}{$(4.38)$} \\
\hline 4 & $\begin{array}{l}\text { ¿Su empresa realiza un aporte periódico, para financiar } \\
\text { nuevas actividades u proyectos de expansión? }\end{array}$ & 4.5 & \\
\hline 5 & $\begin{array}{l}\text { ¿Su empresa estaría dispuesta a realizar un aporte de capital } \\
\text { importante como forma de financiamiento? }\end{array}$ & 4.6 & \\
\hline \multicolumn{4}{|c|}{ Realización de activos } \\
\hline 6 & $\begin{array}{l}\text { ¿En caso de tener equipos inmovilizados, la empresa vende } \\
\text { sus activos para obtener ingresos financieros? }\end{array}$ & 4.45 & \\
\hline
\end{tabular}


¿En caso de tener equipos inmovilizados, la empresa vende $\quad 4.4$ sus activos para invertir en otros bienes?

¿La empresa usa la realización de activos como fuente de financiamiento para la renovación de los mismos?

\section{Utilidades reinvertidas}

\begin{tabular}{clll}
\hline 9 & $\begin{array}{l}\text { ¿La empresa reinvierte las utilidades obtenidas de sus } \\
\text { actividades al finalizar el periodo pactado? }\end{array}$ & 4.6 \\
\cline { 2 - 3 } 10 & $\begin{array}{l}\text { ¿La empresa reinvierte las utilidades obtenidas de sus } \\
\text { actividades para el emprendimientos de nuevos proyectos u } \\
\text { negocios? }\end{array}$ & 4.6 &
\end{tabular}

\section{Financiamiento Público}

\begin{tabular}{|c|c|c|c|}
\hline 11 & ¿Considera que el crédito obtenido se ajusta a sus & 4 & \\
\hline 12 & $\begin{array}{l}\text { ¿Actualmente tiene tratos comerciales con algún banco o } \\
\text { entidad financiera? }\end{array}$ & 4.1 & \\
\hline 13 & $\begin{array}{l}\text { ¿Considera que los requisitos exigidos por su entidad } \\
\text { financiera son un obstáculo para las empresas? }\end{array}$ & 4 & \\
\hline 14 & $\begin{array}{l}\text { ¿Considera usted que la documentación pertinente son un } \\
\text { factor de vital relevancia para obtención del crédito? }\end{array}$ & 4.1 & \\
\hline 15 & $\begin{array}{l}\text { ¿Al momento de solicitar el crédito reunía todos los } \\
\text { requisitos solicitados por la entidad financiera? }\end{array}$ & 4.2 & $(4.27)$ \\
\hline 16 & $\begin{array}{l}\text { ¿Las entidades financieras consideran un riesgo invertir en } \\
\text { las pequeñas MYPES, dado que otorgan muy pocas } \\
\text { garantías de devolución? }\end{array}$ & 4.1 & \\
\hline 17 & $\begin{array}{l}\text { ¿Considera usted que el historial crediticio es un factor de } \\
\text { vital relevancia para obtención del crédito? }\end{array}$ & 4.7 & \\
\hline 18 & $\begin{array}{l}\text { ¿Considera usted que las garantías son un factor de vital } \\
\text { relevancia para obtención del crédito? }\end{array}$ & 4.6 & \\
\hline 19 & $\begin{array}{l}\text { ¿Considera usted que la exigencia de garantías, corresponde } \\
\text { en función al desenvolvimiento del proyecto? }\end{array}$ & 4.6 & \\
\hline
\end{tabular}

\section{Financiamiento Privado}

\begin{tabular}{|c|c|c|}
\hline 20 & ¿Se siente seguro y respaldado por la entidad & 4.2 \\
\hline 21 & $\begin{array}{l}\text { ¿De los instrumentos ofrecidos por las instituciones } \\
\text { financieras, una tasa de interés baja lo llevaría a seleccionar } \\
\text { uno de los instrumentos? }\end{array}$ & 4.7 \\
\hline 22 & $\begin{array}{l}\text { ¿Considera usted que las altas tasas de interés dificultan los } \\
\text { procesos de inversión y crecimiento y generan barreras a la } \\
\text { entrada para nuevos proyectos? }\end{array}$ & 4.7 \\
\hline 23 & $\begin{array}{l}\text { ¿De los instrumentos ofrecidos por las instituciones } \\
\text { financieras, las condiciones de pago y plazo atractivas, lo } \\
\text { levaría a seleccionar uno de los instrumentos? }\end{array}$ & 4.3 \\
\hline
\end{tabular}




\begin{tabular}{|c|c|c|c|}
\hline 24 & $\begin{array}{l}\text { ¿En caso de adquirir un crédito prefiere que sea a largo } \\
\text { plazo? (De } 3 \text { a } 5 \text { años) }\end{array}$ & 4.2 & \\
\hline 25 & $\begin{array}{l}\text { ¿En caso de adquirir un crédito prefiere que sea a mediano } \\
\text { plazo? (De } 1 \text { año a } 3 \text { años) }\end{array}$ & 3.7 & \\
\hline 26 & $\begin{array}{l}\text { ¿En caso de adquirir un crédito prefiere que sea a corto } \\
\text { plazo? ( Menor a } 1 \text { año) }\end{array}$ & 3.9 & \\
\hline 27 & $\begin{array}{l}\text { ¿Considera usted que el monto solicitado es un factor de } \\
\text { vital relevancia para obtención del crédito? }\end{array}$ & 3.4 & $(4.11)$ \\
\hline 28 & $\begin{array}{l}\text { ¿La entidad financiera a la recurrió para el crédito pertenece } \\
\text { al sector público? }\end{array}$ & 4.4 & \\
\hline 29 & $\begin{array}{l}\text { ¿La entidad financiera a la recurrió para el crédito pertenece } \\
\text { al sector privado? }\end{array}$ & 3.8 & \\
\hline 30 & $\begin{array}{l}\text { ¿Se siente satisfecho con el apoyo que recibe de su entidad } \\
\text { financiera? }\end{array}$ & 4 & \\
\hline 31 & $\begin{array}{l}\text { ¿Recurriría nuevamente a la entidad financiera de la que } \\
\text { presto el servicio? }\end{array}$ & 3.5 & \\
\hline 32 & ¿Considera usted que el Perú carece de cultura crediticia? & 4.3 & \\
\hline 33 & $\begin{array}{l}\text { ¿La falta de cultura financiera trae como consecuencia } \\
\text { limitaciones al momento de realizar inversiones cada vez } \\
\text { mayores? }\end{array}$ & 4.2 & \\
\hline 34 & $\begin{array}{l}\text { ¿Ha recibido atención crediticia de entidades públicas? Agro } \\
\text { banco, Banco de la Nación, COFIDE, Fondo Mi Vivienda. }\end{array}$ & 4.3 & \\
\hline 35 & $\begin{array}{l}\text { ¿Ha recibido usted atención crediticia de entidades privadas? } \\
\text { Empresas Bancarias, Empresas Financieras, Cajas } \\
\text { Municipales de Ahorro y Crédito (CMAC), Cajas } \\
\text { Municipales de Crédito y Popular (CMCP), Cajas Rurales de } \\
\text { Ahorro y Crédito (CRAC), Edpymes. }\end{array}$ & 4.2 & \\
\hline
\end{tabular}

Las MYPES del parque industrial de Huaycán usan la depreciación como una de sus principales fuentes de financiamiento, asimismo tienden a usarlos para la renovación de los mismos equipos antes que utilizar el fondo para la adquisición de equipos diferentes.

En cuanto a las utilidades que perciben de ejercicios anteriores, las reinvierten en el mismo negocio, aunque en caso de tener nuevos proyectos los usarían para desarrollarlos.

Por otro lado, en caso de tener equipos inmovilizados, optan por venderlos para obtener ingresos para la adquisición de nuevos equipos, que permitan mejoran la capacidad productiva de la empresa. 
Para las MYPES de zona la aportación de socios se desenvuelve de manera periódica y existe la predisposición a incrementar el capital de la empresa como apoyo a las actividades normales de la empresa y para la expansión de la misma.

\section{Tabla 3}

Resultados de las dimensiones e indicadores del desarrollo empresarial que perciben las MYPES del parque industrial de Huaycan

\begin{tabular}{|c|c|c|c|}
\hline $\mathbf{N}^{\circ}$ & Preguntas & Med & Prom \\
\hline \multicolumn{4}{|c|}{ Personas } \\
\hline 1 & $\begin{array}{l}\text { ¿Usted en los dos últimos años ha invertido en la capacitación } \\
\text { de su personal para brindar un mejor servicio a sus clientes? }\end{array}$ & 4 & \multirow{10}{*}{$(4.02)$} \\
\hline 2 & $\begin{array}{l}\text { ¿Considera usted que la inversión en capacitación de sus } \\
\text { empleados mejoraría la calidad de atención a sus clientes? }\end{array}$ & 4 & \\
\hline 3 & $\begin{array}{l}\text { ¿Considera que el desempeño de sus empleados genera } \\
\text { beneficios a su empresa? }\end{array}$ & 4 & \\
\hline 4 & $\begin{array}{l}\text { ¿El financiamiento ha generado impacto en el área de recursos } \\
\text { humanos de su empresa? }\end{array}$ & 4 & \\
\hline 5 & $\begin{array}{l}\text { ¿Considera que en su empresa se valora la capacidad creativa } \\
\text { de los empleados y esto se ve como una ventaja sobre la } \\
\text { competencia? }\end{array}$ & 4 & \\
\hline 6 & $\begin{array}{l}\text { ¿Considera que el recurso humano ha incrementado en su } \\
\text { negocio? }\end{array}$ & 4 & \\
\hline 7 & $\begin{array}{l}\text { ¿El director de la empresa recibió capacitación antes del } \\
\text { otorgamiento del actual crédito? }\end{array}$ & 4 & \\
\hline 8 & $\begin{array}{l}\text { ¿Ha tenido resultado el número de veces que se ha capacitado } \\
\text { el director de la empresa? }\end{array}$ & 4 & \\
\hline 9 & $\begin{array}{l}\text { ¿Considera usted que la inversión en capacitación del director } \\
\text { mejoraría el manejo del acceso a los créditos? }\end{array}$ & 4 & \\
\hline 10 & $\begin{array}{l}\text { ¿Considera que el nivel de experiencia que tiene actualmente } \\
\text { el director general influye en el manejo de la empresa? }\end{array}$ & 4.2 & \\
\hline
\end{tabular}

\begin{tabular}{llll}
\hline Procesos & & \\
\hline 11 & $\begin{array}{l}\text { ¿Considera que ha incrementado el abastecimiento de materia } \\
\text { prima de sus proveedores? }\end{array}$ & 4.3 \\
12 & $\begin{array}{l}\text { ¿El financiamiento ha generado impacto en los procesos de } \\
\text { producción del producto? }\end{array}$ & 4.5 \\
\cline { 2 - 3 } 13 & $\begin{array}{l}\text { ¿El financiamiento ha generado impacto en la relación con sus } \\
\text { proveedores? }\end{array}$ & 4.3 \\
\cline { 2 - 3 } 14 & $\begin{array}{l}\text { ¿Considera que su empresa considera que es importante } \\
\text { mejorar y agilizar los procesos de negocio de una forma } \\
\text { continua? }\end{array}$ & 4.3 \\
\hline
\end{tabular}




\begin{tabular}{|c|c|c|c|}
\hline 13 & ¿Considera que los costos de su negocio han incrementado? & 4.3 & \\
\hline 14 & $\begin{array}{l}\text { ¿Usted en los dos últimos años ha invertido en investigación y } \\
\text { desarrollo? }\end{array}$ & 4.3 & \\
\hline 15 & $\begin{array}{l}\text { ¿Considera que su empresa busca formas certificadas de llevar } \\
\text { a cabo una mejora continua de sus procesos de negocio? }\end{array}$ & 4.4 & \\
\hline 16 & $\begin{array}{l}\text { ¿Considera que su empresa se busca la certificación de los } \\
\text { procesos y esto nos brinda una ventaja sobre nuestros } \\
\text { competidores? }\end{array}$ & 4.4 & \\
\hline \multicolumn{4}{|c|}{ Tecnología } \\
\hline 17 & $\begin{array}{l}\text { ¿La maquinaria utilizada está apta para cumplir con la } \\
\text { producción establecida? }\end{array}$ & 4.2 & \multirow{5}{*}{$(4.32)$} \\
\hline 18 & $\begin{array}{l}\text { ¿Necesita maquinaria para el desarrollo de la actividad de la } \\
\text { empresa? }\end{array}$ & 4.3 & \\
\hline 19 & $\begin{array}{l}\text { ¿Considera estable la antigüedad de sus equipos como } \\
\text { generador de ingresos? }\end{array}$ & 4.3 & \\
\hline 20 & $\begin{array}{l}\text { ¿Realizar los mantenimientos respectivos a la maquinaria le } \\
\text { genera rentabilidad a la empresa? }\end{array}$ & 4.4 & \\
\hline 21 & ¿Qué impacto ha generado el financiamiento en tecnología? & 4.4 & \\
\hline \multicolumn{4}{|c|}{ Producto } \\
\hline 22 & $\begin{array}{l}\text { ¿Considera que la demanda del producto o servicio que ofrece } \\
\text { su negocio ha incrementado? }\end{array}$ & 4.4 & \multirow{4}{*}{$(4.40)$} \\
\hline 23 & $\begin{array}{l}\text { ¿Considera usted que en los dos últimos años ha brindado una } \\
\text { mejor calidad de sus productos o servicios a sus clientes? }\end{array}$ & 4.3 & \\
\hline 24 & $\begin{array}{l}\text { ¿Usted ha brindado en los dos últimos años precios inferiores a } \\
\text { la competencia de productos y servicios? }\end{array}$ & 4.5 & \\
\hline 25 & $\begin{array}{l}\text { ¿Usted ha desarrollado en los dos últimos años nuevos } \\
\text { productos o servicios? }\end{array}$ & 4.4 & \\
\hline
\end{tabular}

\begin{tabular}{|c|c|c|c|}
\hline \multicolumn{4}{|c|}{ Ingresos } \\
\hline 26 & $\begin{array}{l}\text { ¿Considera que la inversión en su capital de trabajo se ha } \\
\text { incrementado? }\end{array}$ & 4.4 & \multirow{7}{*}{$(4.34)$} \\
\hline 27 & $\begin{array}{l}\text { ¿De acuerdo al financiamiento obtenido su negocio ha } \\
\text { mejorado? }\end{array}$ & 4.6 & \\
\hline 28 & $\begin{array}{l}\text { ¿Cree que el financiamiento que le ha sido otorgado, ha } \\
\text { mejorado la rentabilidad de su empresa? }\end{array}$ & 4.3 & \\
\hline 29 & $\begin{array}{l}\text { ¿Usted en los dos últimos años ha accedido a nuevos } \\
\text { mercados? }\end{array}$ & 4.3 & \\
\hline 30 & $\begin{array}{l}\text { ¿Considera que el nivel de ventas en su negocio ha } \\
\text { incrementado? }\end{array}$ & 4.2 & \\
\hline 31 & $\begin{array}{l}\text { ¿Considera que su empresa utiliza o ha utilizado apoyos } \\
\text { gubernamentales para mejorar su competitividad? }\end{array}$ & 4.3 & \\
\hline 32 & $\begin{array}{l}\text { ¿Considera que la estabilidad económica de la región estimula } \\
\text { la competitividad de nuestra empresa? }\end{array}$ & 4.3 & \\
\hline
\end{tabular}


Las MYPES del parque industrial de Huaycan consideran que las personas son un elemento importante que contribuye al desarrollo de la empresa; regularmente los capacita, y están dispuestos a seguir invirtiendo en el capital humano dado que son conscientes de que la capacitación, les proporciona una herramienta competitiva.

En cuanto a los procesos, las MYPES consideran que el financiamiento recibido ha mejorado sus procesos productivos; asimismo, consideran importante la mejora continua como parte del desarrollo de sus procesos dado que serán más competitivos a medida que estén mejor preparados y tengan más capacidad.

Por otro lado, con respecto a la tecnología, el financiamiento ha facilitado su adquisición, las MYPES se preocupan por su mantenimiento y óptimo funcionamiento. Si bien es cierto sus equipos cumplen sus requerimientos, también optarían por la adquisición de otros que mejoren los procesos.

Para las MYPES, el desarrollo de sus productos es muy importante, han mejorado sus precios sin mermar la calidad, por lo que han incrementado su demanda, y han apoyado estas mejoras con la adición y desarrollo de nuevos productos que cumplan con los requerimientos de sus clientes.

Las MYPES de la zona indican que el financiamiento ha apoyado el incremento de sus ingresos, asimismo su incursión a nuevos mercados, mejorando la rentabilidad de la empresa e incrementando su capital de trabajo.

\section{Tabla 4}

Alcance de los niveles de desarrollo de las MYPES del parque industrial de Huaycan

\begin{tabular}{|l|c|c|c|}
\hline \multirow{2}{*}{$\begin{array}{l}\text { Niveles de desarrollo de las } \\
\text { MYPES }\end{array}$} & \multicolumn{3}{|c|}{ Alcance } \\
\cline { 2 - 4 } & Bajo & Medio & Alto \\
\hline Personas & $61.7 \%$ & $15.0 \%$ & $23.3 \%$ \\
Procesos & $36.7 \%$ & $45.0 \%$ & $18.3 \%$ \\
Tecnología & $51.7 \%$ & $23.3 \%$ & $25.0 \%$ \\
Producto & $58.3 \%$ & $20.0 \%$ & $21.7 \%$ \\
Ingresos & $46.7 \%$ & $28.3 \%$ & $25.0 \%$ \\
\hline Desarrollo Empresarial & $31.7 \%$ & $41.7 \%$ & $26.7 \%$ \\
\hline
\end{tabular}




\section{Tabla 5}

Relación entre el financiamiento y el desarrollo de las MYPES del parque industrial de Huaycán

\begin{tabular}{lccl}
\hline \multicolumn{3}{c}{ Desarrollo Empresarial } \\
\hline & Rho de Spearman & P valor & N \\
\hline Financiamiento & $.329^{*}$ & .036 & 60 \\
\hline *. La correlación es significativa en el nivel 0,05 (2 colas).
\end{tabular}

Entonces, con un nivel de significancia menor al 0,05 (p- valor $=0,000)$, se rechaza la hipótesis nula y se acepta la hipótesis de investigación, También con un coeficiente de correlación Rho de Spearman de 0.329 se determina que existe una correlación positiva media entre el financiamiento y el desarrollo empresarial de las MYPES del parque industrial de Huaycán durante el periodo 2018.

\section{Tabla 6}

Relación entre el financiamiento y el producto para un mejor desarrollo empresarial en las MYPES del parque industrial de Huaycán

\begin{tabular}{lccc}
\hline \multicolumn{3}{c}{ Dimensión de Desarrollo empresarial } \\
\hline \multicolumn{3}{c}{ Producto } \\
\hline Rho de Spearman & P valor & N \\
\hline Financiamiento & .322 & .043 & 60 \\
\hline *. La correlación es significativa en el nivel 0,05 (2 colas). &
\end{tabular}

Entonces, con un nivel de significancia menor al 0.05 (p- valor $=0,000)$, se rechaza la hipótesis nula y se acepta la hipótesis de investigación, También con un coeficiente de correlación Rho de Spearman de 0.322 se determina que existe una correlación positiva media entre el financiamiento y el producto según el desarrollo empresarial de las MYPES del parque industrial de Huaycán durante el periodo 2018.

Esta correlación es mediana, por lo que, al mejorar la calidad de los productos, se logra una alta satisfacción en el cliente, lo que implica su preferencia, por considerarlo con mejores sus ventajas y rendimiento sobre los productos ofrecidos por la competencia (Uribe y López, 2012). 


\section{Tabla 7}

Relación entre el financiamiento y los procesos para un mejor desarrollo empresarial en las MYPES del parque industrial de Huaycán

\begin{tabular}{|c|c|c|c|}
\hline \multicolumn{4}{|c|}{ Dimensión de Desarrollo empresarial } \\
\hline & \multicolumn{3}{|c|}{ Procesos } \\
\hline & Rho de Spearman & $\mathbf{P}$ valor & $\mathbf{N}$ \\
\hline Financiamiento & .890 & .579 & 60 \\
\hline
\end{tabular}

Entonces, con un nivel de significancia mayor al 0,05 (p- valor=0,000), se acepta la hipótesis nula y se rechaza la hipótesis de investigación. También, con un coeficiente de correlación Rho de Spearman de 0.890 se determina que existe una correlación negativa alta entre el financiamiento y los procesos según el desarrollo empresarial de las MYPES del parque industrial de Huaycán durante el periodo 2018.

Esta correlación es la más alta si la comparamos con las otras dimensiones, pero ha sido rechazado, por lo que, dentro de las MYPES, la inversión en los procesos no sería un aspecto relevante. Sin embargo, para que las empresas sean rentables y competitivas, se debe implementar mejoras en los procesos de la empresa, para un mejor aprovechamiento de sus recursos, y optimizar las ventas e ingresos, López y Camacho (2013).

\section{Tabla 8}

Relación entre el financiamiento y las personas para un mejor desarrollo empresarial en las MYPES del parque industrial de Huaycán

\begin{tabular}{|c|c|c|c|}
\hline \multicolumn{4}{|c|}{ Dimensión de Desarrollo empresarial } \\
\hline \multicolumn{4}{|c|}{ Personas } \\
\hline & Rho de Spearman & $\mathbf{P}$ valor & $\mathbf{N}$ \\
\hline Financiamiento & .112 & .487 & 60 \\
\hline
\end{tabular}

Entonces, con un nivel de significancia mayor al 0,05 (p- valor=0,000), se acepta la hipótesis nula y se rechaza la hipótesis de investigación, También con un coeficiente de correlación Rho de Spearman de 0.112 se determina que existe una correlación 
negativa baja entre el financiamiento y los personas según el desarrollo empresarial de las MYPES del parque industrial de Huaycán durante el periodo 2018.

Esta correlación es la más baja si la comparamos con las otras dimensiones. Por lo tanto, se podría inferir que en cuanto a la inversión en el capital humano requieren plantear iniciativas de mejora y apoyo constante. Siendo que el factor humano es la herramienta clave para poder competir y ganar un mercado dado, ya que el involucramiento del desempeño de cada miembro permite un mejor desarrollo empresarial y logra establecer una estrategia competitiva global (Librado, 2014).

\section{Tabla 9}

Relación entre el financiamiento y la tecnología para un mejor desarrollo empresarial en las MYPES del parque industrial de Huaycán

\begin{tabular}{|c|c|c|c|}
\hline \multicolumn{4}{|c|}{ Dimensión de Desarrollo empresarial } \\
\hline \multicolumn{4}{|c|}{ Tecnología } \\
\hline & Spearman & P valor & $\mathbf{N}$ \\
\hline Financiamiento & 0.351 & .026 & 60 \\
\hline
\end{tabular}

Entonces, con un nivel de significancia menor al 0,05 (p- valor=0,000), se rechaza la hipótesis nula y se acepta la hipótesis de investigación, También con un coeficiente de correlación Rho de Spearman de 0.351 se determina que existe una correlación positiva media entre el financiamiento y la tecnología según el desarrollo empresarial de las MYPES del parque industrial de Huaycán durante el periodo 2018.

Esta correlación es mediana, por lo que, al invertir en tecnología en cada unidad productiva se genera una sinergia que busca reducir costos de mano de obra y se suman al mundo de desarrollo e investigación, el cual le permite una idea de innovación donde le es necesario acudir a la mejora y lograr competitividad en el mercado (MTEP, 2006).

\section{Tabla 10}

Relación entre el financiamiento y el nivel de ingreso para un mejor desarrollo empresarial en las MYPES del parque industrial de Huaycán

\begin{tabular}{lll}
\hline \multicolumn{3}{c}{ Dimensión de Desarrollo empresarial } \\
\hline \multicolumn{3}{c}{ Nivel de ingresos } \\
\hline Rho de Spearman & P valor & N \\
\hline
\end{tabular}


*. La correlación es significativa en el nivel 0,05 (2 colas).

Entonces, con un nivel de significancia mayor al 0,05 (p- valor $=0,000)$, se acepta la hipótesis nula y se rechaza la hipótesis de investigación, También con un coeficiente de correlación Rho de Spearman de 0.233 se determina que existe una correlación negativa baja entre el financiamiento y el nivel de ingresos según el desarrollo empresarial de las MYPES del parque industrial de Huaycán durante el periodo 2018.

Esta correlación es una de las más bajas si la comparamos con las otras dimensiones. Por lo tanto, se podría inferir que el financiamiento no fue favorable debido a que los ingresos corresponden a la venta de los productos y servicios, y si estos no cumplen con las necesidades o requerimientos de los clientes se afecta la demanda. Según Martínez (2014) esta se clasifica como ingreso a todo incremento de demanda que se han alcanzado como consecuencia de la comercialización de productos o por la prestación de servicios, igualmente a las utilidades recopiladas por los ejercicios económicos.

\section{Discusión}

En los resultados de la investigación, se encontró una correlación significativa media de 0.329. El financiamiento incide favorablemente en el desarrollo empresarial de las MYPES, fomentando la inversión en las distintas áreas de la empresa, para mejora integral de la organización, a nivel de personas, procesos, tecnología, productos e ingresos. Se propone que se dé capacitaciones continuas para generar nuevos proyectos de mejora para cada área dentro de la empresa. Por ello, se sugiere realizar posteriores investigaciones de las variables de financiamiento y desarrollo empresarial con otro enfoque poblacional.

Para los resultados del financiamiento y el producto, se encontró una correlación significativa media de 0.322 que demuestra una relación positiva y directa. El financiamiento se relaciona favorablemente con el producto, las empresas invierten para que sea de mejor calidad, asimismo se preocupan por su mejora cualitativa y la percepción de calidad al momento de llegar al cliente.

Para el financiamiento y los procesos, se encontró una correlación significativa media de 0.890; sin embargo, el p valor tuvo como resultado 0.579 ( $\mathrm{p}<0.05$ ) lo que 
indica que el financiamiento no se relaciona favorablemente con los procesos, lo cual es un aspecto preocupante dado que los procesos son vitales para el orden de la organización, dado que los procesos proponen los pasos para lograr óptimos resultados como empresa.

En cuanto a la relación entre el financiamiento y las personas, se encontró una correlación significativa débil de 0.112 que demuestra que no existe una relación significativa entre las variables. Con este resultado se entiende que el financiamiento no se relaciona favorablemente en las personas para un mejor desarrollo.

Con respecto a la relación del financiamiento y la tecnología, se encontró una correlación significativa media de 0.351 que demuestra que existe una relación positiva y directa. Asimismo, en cuanto a la relación del financiamiento y el nivel de ingresos, se encontró una correlación significativa débil de 0.233. Esto es causado por la que están enfocando el financiamiento en el producto y la tecnología, descuidando los procesos y las personas.

La correlación entre el financiamiento y el desarrollo de las MYPES del parque industrial de Huaycán reveló un coeficiente de 0.329 , este resultado se acerca al obtenido por Márquez (2007) quien mide el financiamiento y sus efectos en las pequeñas y medianas empresas, donde se obtuvo mediante la prueba de Rho de Spearman un coeficiente de 0.37 .

Por otro lado, se asoció el financiamiento y el desarrollo de las MYPES del parque industrial de Huaycán, lo cual se midió a través del coeficiente de correlación Rho de Spearman, teniendo como resultado en la prueba de hipótesis una relación significativa media de 0.329, que estadísticamente significa que existe una correlación positiva media. Por lo tanto, se puede aseverar que el financiamiento cumple un rol importante en el desarrollo empresarial de las MYPES.

En resumen, existe una relación significativa positiva media entre el financiamiento y el desarrollo empresarial de MYPES (Rho de Spearman= 0,329). Asimismo, existe una relación significativa positiva media entre el financiamiento y el producto según el desarrollo empresarial de MYPES (Rho de Spearman=0,322).

\section{Referencias}

Algieri, M. A. (2007). Alternativas de financiamiento para la pequeña y mediana empresa (Pyme) de las industrias metálicas y metalmecánicas en Barquisimeto, Estado Lara. 
Cornejo L. R. A. y Galicia Q. M. (2010). Las instituciones micro financieras: ¿Satisfacen los microempresarios en el Distrito Federal? Congreso Internacional de Contaduria, Administracion e Informatica, 1-27.

García P. D. (2003). Análisis estratégico para el desarrollo de la pequeña y mediana empresa. Subdirección de Análisis e Investigación, Universidad de Murcia.

Garma L. (2006). Parque industrial $N^{\circ} 1$ de Huaycán, Lima, Perú: Asociación PYME, Perú. Recuperado de: https://www.asociacionpyme.pe/nuestros gremios/parqueind ustrial/

Jimenez M. W, Luciano A. A. y Soto C. C. (2014). Influencia de las fuentes de financiamiento en el desarrollo de las empresas agroindustriales del distrito de Abancay y Apurimac Peru (periodo 2012-2013). Revista de investigaciones $U N A D, 13(1), 261-273$.

Kong R. J. A., y Quilcate M. J. M. (2014). Influencia de las fuentes de financiamiento en el desarrollo de las MYPES del distrito de san José - Lambayeque en el período 2010-2012 (Tesis de licenciatura). Universidad Catolica Santo Toribio de Mogrovejo, Chiclayo, Perú.

La Republica (2012). Programa de Mypes redujo a 7\% pobreza extrema en Huaycan en un año, Lima, Peru. Diario La Republica. http//:larepublica.pe/economia/661534programa-de-mypes-redujo-a-7-probreza-extrema-en-huaycan-en-un-ano.

López, A. y Camacho O. (2013). Estudio del flujo de efectivo enfocado a una empresa de distribución de artesanías en México. (Tesis de licenciatura). Instituto Politécnico Nacional, México D. F.

Librado R. F. (2014). Financiamiento para las MYPES en México.

Marquez C. L. E. (2007). Efectos del financiamiento en las medianas y pequeñas empresas. (Tesis de licenciatura). Universidad Privada San Martín de Porres, Lima, Perú.

MTPE. (2006). La microempresa: una propuesta tipológica y ejercicio de aplicación en Lima Sur. Boletín Laboral 34, 1-70.

Tovar A. (2015). Centro de Servicios de Desarrollo Empresarial en el Distrito de ATE LIMA, PERU, ADECT-ATC. Asociación laboral para el desarrollo

Uribe F. A. C. y López A. N. L. (2012). Fuentes de financiamiento utilizadas por las medianas y grandes empresas de Pereira y Dosquebradas en los años 2010 a 2011. (Tesis de licenciatura). Universidad Católica de Pereira. Risaralda, Colombia. http//doi.org/10.1073/pnas.0703993104 